\title{
Prevalence of Depression in Postmenopausal Women
}

\author{
Poorandokht Afshari ${ }^{1}$; Sedighe Manochehri ${ }^{1, *}$; Mitra Tadayon ${ }^{1}$; Mahbobeh Kianfar ${ }^{1}$; \\ Mohammadhosain Haghighizade ${ }^{2}$
}

${ }^{1}$ Department of Nursing, Nursing and Midwifery School, Ahvaz Jundishapur University of Medical Sciences, Ahvaz, IR Iran ${ }^{2}$ Department of Health, Ahvaz Jundishapur University of Medical Sciences, Ahvaz, IR Iran

*Corresponding author: Sedighe Manochehri, Department of Nursing, Nursing and Midwifery School, Ahvaz Jundishapur University of Medical Sciences, Ahvaz, IR Iran. Tel: +98-9367724855; +98-6133738477, E-mail: sedighemanochehri20@yahoo.com

Received: January 30, 2015; Revised: March 10, 2015; Accepted: April 7, 2015

Background: Every woman during different stages of her growth faces various crises, and one of these crises, menopause, may create different problems. In modern societies, psychological disorders and particularly depression is one of the problems of menopausal women.

Objectives: This study aimed to evaluate the prevalence of depression in postmenopausal women referred to selected health centers of Ahvaz in 2014.

Patients and Methods: This study was cross-sectional study. In this study, 1280 postmenopausal women aged between 40 and 65 years old who were referred to selected health centers of Ahvaz in 2014 were randomly enrolled. Hamilton depression scale and demographic questionnaire were used for gathering information. Data were analyzed using SPSS software. To analyze the data, descriptive statistics and analytical statistics (Independent t test, ANOVA, Pearson correlation and logistic regression) were carried out (CI 95\%).

Results: The mean \pm SD score of depression for the subjects was $9.37 \pm 4.62$. The results showed that $59.8 \%$ of the 1280 samples were depressed; in particular, $39.8 \%$ had mild depression, $16 \%$ moderate depression, and $4 \%$ severe depression. There is a significant and inverse relation between variables of age, exposure to cigarette smoking, and the relationship with their spouses and the level of their depression, so higher age, more exposure to smoking, and better relation with their husbands, lead to the less depression. The results showed that the level of education is associated with depression. The highest rate of depression was in illiterate women; the finding also showed that there is a relationship between income and the severity of depression (Regression Log). T test showed that the mean depression level of employed postmenopausal women is higher than housewives postmenopausal women, and this difference is statistically significant $(\mathrm{P}$ $<0.001$ ).

Conclusions: A significant percentage of women in their menopause experience depression. This depression can be associated with variables such as exposure to cigarette smoke, certain personal characteristics (e.g. relationship with spouse), and socioeconomic status (education, income).

Keywords: Menopause; Depression; Menopause; Depression; Menopause; Depression; Prevalence

\section{Background}

Psychological problems and particularly depression is one of problems menopausal women face in the modern societies. Depression is one of the most common psychiatric disorders, which is not limited to specific time, place, or person and includes all groups and classes of society (1). Depression can be followed by some side effects and problems that leads to psychological and physical problems in the family and finally suicide, which is usually seen in untreated depression (2). The prevalence of this disorder in women is about two times than its prevalence in men of any age (3). Cooke and Ancoli-Israel (4) believe that menopause in women is associated with increased depressive symptoms, as the maximum prevalence rate of depression is around premenopausal stage due to higher hormonal fluctuations. Strine et al. (5) also believe that premenopausal period and the beginning of menopausal changes are related with the increased risk of depression. In the study by Blumel et al.(6) $46.5 \%$ of enrolled menopausal women in the study were depressed. In Reed et al. (7), the rate of this disorder was $18 \%$. The prevalences of depression of menopausal women were reported differently in various parts of Iran. In a study conducted by Yassary et al. (8) in Dezful, the prevalence of depression of postmenopausal women was 34.7\%. In another research in Tabriz on postmenopausal women by Taroyardi et al. (9), 68\% of participants had moderate depression. Researchers in the other study in Kermanshah, have estimated that the prevalence of depression of postmenopausal women was $32.5 \%$ (10). In the study of Timur and Shahin (11) the prevalence of depression was 41.8\% before and after menopause.

Several causes underlying the depression associated

Copyright (C) 2015, Ahvaz Jundishapur University of Medical Sciences. This is an open-access article distributed under the terms of the Creative Commons Attribution-NonCommercial 4.0 International License (http://creativecommons.org/licenses/by-nc/4.0/) which permits copy and redistribute the material just in noncommercial usages, provided the original work is properly cited. 
with menopause. Some of these factors include previous history of depression; personal, and cultural issues; losing the role of being a mother, husband inevitable death, negative attitudes toward menopause, long term menopause, and so on $(12,13)$. Some researchers (14) believe that depression during menopause occurs because of decrease in gonadal hormone levels, which subsequently leads to fatigue, loss of sleep, and nighttime hot flashes. Whereas others believe that depression in this age is more related to psychosocial events such as changes in relationships with children, marital status, and other life events (15). On the other hand, some researchers expressed the biopsychological factors, the relationship with husband, educational level, race, and demographic factors, as related factors to depression during menopause (16). Another study has shown that women who have longer premenopausal period, experience more depressive symptoms (17). Some other researchers have also reported that high levels of stress and anxiety are capable of exacerbating the symptoms of menopause. For example, unpleasant life events are associated with more severe symptoms of menopause (18). In a study conducted in 2009, Graziottin and Serafini concluded that postmenopausal women who are at low social, economic, and ethnic level have the greatest degree of depression (19). Although in older texts, depression and menopause are linked to each other, there is little evidence about this relationship, and the relationship between depression and altered levels of sex hormones, like those occur during menopause, is still a controversial issue and it is not clear how mood symptoms are connected to menopause (13). In most cases, some physiological and pathological changes create these problems during menopause (20); however, the attitude of women about menopause has an important role in the creation or elimination of the problems (12). In this regard, it has been seen that many women consider menopause as the emancipation time because of the end of reproductive years, no responsibility for children, or fear of pregnancy, so they feel more comfortable and seem to be more sexually active than before. However, for most women, the arrival of this period bring up their concern; for them it is a visible sign of aging and the end of their appeal (21). The menopause can be a factor in the creation, duplication, or discharging of sexual problems during reproductive period and therefore lead to depression (22). The results of research conducted by Veras et al. (23), (using Beck test) showed that depression and anxiety increase in women during menopause. In general, review of studies on the relationship between menopausal symptoms with psychological disorders such as anxiety and depression shows that these studies have conflicting results.

However, treatment of depression and anxiety, in addition to the economic burden imposed on families and society reduces the quality of life in postmenopausal women. Therefore, the quality of life in postmenopausal women is considered an important health issue in dif- ferent societies and one of the basic goals of health care system. If certain symptoms of menopause such as hot flashes and night sweats can be the underlying cause of psychological disorders such as anxiety and depression, with treatment of these symptoms, depression and anxiety can be easily prevented and therefore, the quality of life postmenopausal women can be improved (3).

\section{Objectives}

Given that in recent decades, women's life expectancy has increased and more women are going through menopause and on the other hand, patients with depression have higher costs of medical care, including hospital care and laboratory tests, the diagnosis and treatment of depression associated with menopause will have a significant effect on reducing overall health costs. Therefore, we should pay more attention to this group of women and accordingly the aim of this study was to evaluate the prevalence of depression in postmenopausal women referred to the selected health centers of Ahvaz in year 2014.

\section{Patients and Methods}

This study is a descriptive-analytical study and conducted to assess depression prevalence in postmenopausal women of 40 to 65 years old who were referred to selected health centers of Ahvaz in 2013 - 2014. Sampling was done randomly and continuously. The sample size calculation was based on the study of Taavoni and colleagues in 2011 (24) and consultation with the master data using the formula (Equation 1):

$$
N=\frac{p(1-p) \frac{z^{2} a}{2}}{d^{2}}
$$

(CI 95\%, Power $=80 \%)$.

Considering the aforementioned calculations, 1280 qualified volunteers were recruited and data were collected by interview after mentioning the purpose of the study and taking the informed consent form. Inclusion criteria for the study were postmenopausal women (at least one year passed from their last menstruation) with 40 - 65 years old. In this study, 1280 postmenopausal women referred to health centers of the Ahvaz City having met the inclusion criteria were selected by random sampling. Since there are two healthcare treatment centers in Ahvaz, located in the east and the west of the city (each including many infirmaries). Six sub-centers selected randomly including health care sub-centers number one, three and nine from the east and numbers three, four and eight from the west. Then number of households of each center was determined in accordance with each region and finally, 1280 patients (total sample size) were selected from all centers. The number of women selected from each center was proportionate to the number of families living within the area. Therefore, the great- 
er the population covered by a center, the more would be the selected women from that center. Selection of the menopausal women was carried out by referring to the available family files and writing down their addresses and telephone numbers. Then, these families were visited, and the questionnaire was completed by interviewing the menopausal women. If nobody was found at any of these addresses, the neighbor on the left-hand side or on the right-hand side was selected as the substitute. This process continued until the sample size was achieved. Before completing the questionnaire, the participants were presented necessary explanations. Then, the interviews were conducted after obtaining their oral and written consent, and informing them their confidentiality, as well as their freedom to leave the interview at any moment. Tools used in this study, were a demographic questionnaire consisted of 18 items and the Hamilton Depression Scale contains 24 items. Hamilton Depression Scale consists of 17 - 21 observation items of measurements, which measures the presence and the severity of depression. For every question characterizing a disease symptom, there are 4 written statements, which respectively represent the mildest to the most severe form of sick feeling. The value of every aspect is rated from 0 to 4. The following scores are considered to determine the overall level of depression in this study, normal 0 - 7, 8 13 mild depression, 14 - 18 moderate depression, and $\geq 19$ severe depression. The reliability of Hamilton questionnaire (in a conducted study on 70 patients by Hamilton) in terms of correlation coefficients received the number of 0.90 by two assessors. In another study, this ratio was equal to 0.94 . Validity and reliability of the information obtained from the Hamilton rating scale for depression are highly correlated with the data obtained from the National Institute of Mental Health Diagnostic Interview $(25,26)$. Data were analyzed using SPSS software; descriptive and inferential statistics were used for data analysis (Independent t test, 1-way ANOVA, Pearson correlation, and logistic regression).

\section{Results}

The mean ages of studied postmenopausal women were $55.27 \pm 3.03 \mathrm{y}$, their postmenopausal ages: $50.8 \pm$ $1.71 \mathrm{y}$, the average number of years since menopause: 2.31 $\pm 4.43 \mathrm{y}$, and the mean score of depression in the study population: $9.37 \pm 4.62$ (Table 1). About 58.7\% of women were illiterate, $48.6 \%$ were exposed to cigarette smoke, and $50.6 \%$ of women had a relationship with their spouse (Table 2). The results showed that $59.8 \%$ of the sample (in 1280 women) were depressed, in particular, $39.8 \%$ had mild depression, $16 \%$ moderate depression, and $4 \%$ severe depression (Table 3). The findings in Table 4 indicate that the age, exposure to smoking, and the relationship with husband have significant and inverse relationships with severe depression, i.e. being older and longer exposure to smoking and relationship with spouse, the less would be the degree of depression. The results also showed that the degree of education was associated with depression. The highest rates of depression were seen in illiterate women; the finding also showed that there was a relationship between income and the severity of depression (Table 4) $(\mathrm{P}<0.001)$. T test showed that the mean depression in working menopausal women (10.64 \pm 5.11$)$ is higher than housewife ones $(0.10 \pm 4.47)$, and this difference is statistically significant $(\mathrm{P}<0.001)$.

Table 1. Average of Some Demographic Variables and Depression Scores (Descriptive Statistics)

\begin{tabular}{lc}
\hline Variable & Mean \pm SD \\
\hline Age, $y$ & $55.27 \pm 3.03$ \\
Menopause age, $y$ & $50.8 \pm 1.72$ \\
\hline Number of years past since menopause & $4.43 \pm 2.31$ \\
Depression score & $9.37 \pm 4.62$ \\
\hline
\end{tabular}

Table 2. The Distribution of Some Variables (Descriptive Statistics)

\begin{tabular}{lc}
\hline Variable & No. $(\%)$ \\
\hline Education & $751(58.7)$ \\
\hline Illiterate & $529(41.3)$ \\
\hline literate & \\
\hline Exposed to cigarette smoke & $504(39.4)$ \\
\hline A little & $97(7.6)$ \\
\hline Average & $22(1.7)$ \\
\hline A lot & \\
\hline Occupation & $1058(82.7)$ \\
\hline Housewife & $222(17.3)$ \\
\hline Employed & \\
\hline Monthly income & $605(47.3)$ \\
\hline More than 335 USD & $673(52.6)$ \\
\hline Less than 335 USD & \\
\hline Relationship with spouse & $144(11.3)$ \\
\hline No relationship & $241(18.8)$ \\
\hline Very satisfied & $589(46)$ \\
\hline Satisfied & $271(21.2)$ \\
\hline Moderately satisfied & $35(2.7)$ \\
\hline Unsatisfied & \\
\hline
\end{tabular}

Table 3. Distribution of Depression (Descriptive Statistics)

\begin{tabular}{lc}
\hline Level of depression & No. (\%) \\
\hline No depression & $514(40.2)$ \\
\hline Mild & $501(39.8)$ \\
Moderate & $205(16)$ \\
Severe & $51(4)$ \\
\hline
\end{tabular}


Table 4. Correlation of Depression With Age, Exposure to Smoking, Relationship With the Spouse, Monthly Income, and Education Level of the Study Sample (Logistic Regression)

\begin{tabular}{lcc}
\hline Variable & \multicolumn{2}{c}{ Depression } \\
\cline { 2 - 3 } & P Value & $\mathbf{r}$ \\
\hline Age & 0.008 & 0.074 \\
Exposure to cigarettes & 0.0001 & 0.130 \\
Relationship with spouse & 0.0001 & 0.259 \\
Monthly income & 0.048 & 0.053 \\
Education & 0.044 & 0.056 \\
\hline
\end{tabular}

\section{Discussion}

The mean depression score of subjects in this study was $9.37 \pm 4.62$. Menopause age of the studied population was $50.8 \pm 1.71 \mathrm{y}$. Menopause age in several studies were reported differently (due to different factors that affect menopause), but generally the mean menopause age is around 45 to 52 years (12). According to a previous study, the usual age for the onset of depression disorders was around 40 years old and its prevalence increases with age; menopause also occurs around this age. Several reasons underlie depression associated with menopause such as negative attitudes toward menopause, and longterm menopause changes in sexuality, and menopausal symptoms such as hot flashes, night sweats, and secondary sleep disorders (12).

The prevalence of depression during menopause has been reported differently in various studies. Much research has been done in the field of depression and menopause, including the study by Shojaiyan et al. (27), in which the mean depression scores of the subjects was $9.7 \pm 4.19$, which is similar to our study. About $59.8 \%$ of the subjects in the study had depression (mild, moderate, and severe). Study by Polisseni et al. (28) in Brazil reported the prevalence of depression during menopause as $40 \%$. In Yassary et al. study, this figure was $34.7 \%$ (8). In the other study, $46.5 \%$ of subjects in the study were suffering from depression (6). In a study conducted by Dolatian et al. (10) about the prevalence of depression and its related factors at different stages of menopause among women residing in Kermanshah, it was found that 32.2\% of the subjects were depressed. According to the stages of menopause, the highest prevalence of depression was $39.3 \%$ seen in perimenopausal women and the least prevalence was $21.6 \%$ among premenopausal women (10). The different results may be due to factors such as culture, religion, race, and attitude.

Some scholars such as Llaneza et al. (16) believe that biopsychological factors, the relationship with the partner, stress, level of education and demographic factors could be the affecting factors in the prevalence of depression in middle-aged women. Findings of our research in Tables 3 and 4 show that there is a significant relation between the age and the exposure to smoking and the relationship with Spouse and job of the subjects with the levels of depression. Yaktatalab et al. (29) showed that there was a significant relationship between the age and decrease in score depression as in younger women it was more; which was consistent with our research. While in the study of Yassary et al. (8), we see that there is no significant relation between age, age at onset of menopause, menopausal duration and the job of the subjects with depression.

Some researchers like Dennerstein et al. (30) have pointed out the relationship of smoking and increased rates of depression. Our study showed that the more women were exposed to smoking the less would be depression, which was inconsistent with his research. The results of Yassary et al. (8) showed that the relationship with spouse would affect depression level. Those wives who have dispute with their husbands are more depressed, and have more aggressive behavior and anxious mood. Li et al. (31) showed that those who have a dispute with her spouse during menopause are more likely to develop depression. Cuadros et al. (32) (Spain) also showed that the better relationship of menopausal women with their spouse, the less they experience stress. In our research, $P$ value was equal to 0.001 , which indicated a significant relationship between depression and relationship with spouse, which is similar to his research. The results showed that $64.8 \%$ of those surveyed feel satisfaction of their relationship with their spouse. Findings of Bahri et al. (3) showed $58.8 \%$ relationship between the severity of menopausal symptoms in postmenopausal women and depression as well as stress. They stated that they have a good emotional relationship with their spouse, which is comparable with our study results (3). The results showed that the level of education is associated with depression. The highest rates of depression were in illiterate women. Study of Yassary et al. (8) shows the same result. Another research has found that low level of education associates with higher depression in menopause (33). The study also showed that there is a relationship between income and the severity of depression. Other studies have also shown that low economic status can increase psychiatric disorders in menopause $(8,18,31,34)$.

In the machine era, mental illness and discomfort can happen to all individuals. Depression is a disease that is more common in women. This study showed that a significant percentage of women experiencing depression in their menopause. This depression can be associated with certain personal characteristics (e.g. relationship with spouse), socioeconomic status (education, income) and being exposed to cigarette smoke. Depression in women can cause disability, impair their interpersonal, and social functions and career and also incur high cost to health care system. Thus, the diagnosis of depression and its relevant individual, social, and economic factors in women and providing training and advice from the experts to the family and society would be helpful. 


\subsection{Applicability Results}

Healthcare providers by considering the characteristics that put individuals in risk group could prevent or improve depression in postmenopausal women. Further research are recommended to be performed in the field (menopause and depression) which may have impact in reducing complications of menopausal women, especially depression during this time. This research was conducted on postmenopausal women residing in Ahvaz City. It is suggested that this research be done in wider population and different parts of the country.

\subsection{Weaknesses of the Study}

Relationship with spouse cannot be measured.

\subsection{Study Limitations}

Because of the large sample size (1280 postmenopausal women), it was difficult for the researcher to find all this huge number of people. In the face of this problem, researchers asked the permission and assistance of the health care centers authorities, in this particular issue regarding postmenopausal women. Another limitation of this study was the absence of spontaneous postmenopausal women in the health centers and study sample. This limitation was partially resolved by health intermediators.

\subsection{Study Code Ethic}

The study was approved by the Ethics Committee of Ahvaz Jundishapur University of Medical Sciences (Ajums. REC.1393.278).

\section{Acknowledgements}

We appreciate dear colleagues, faculty members and staff of the selected health centers of the city of Ahvaz, which contributed in this research as well as all women who participated in this study and answered our questionnaire.

\section{Authors' Contributions}

Sedighe Manochehri; Poorandokht Afshari; Mitra Tadayon; Mahbobeh Kianfar; and Mohammadhosain Haghighizade: Conception and Design; Sedighe Manochehri: Preparation of Multimedia Software; Sedighe Manochehri and Mahbobeh Kianfar: Data Collection; Sedighe Manochehri and Mohammadhosain Haghighizade: Statistical analysis And Interpretation; Sedighe Manochehri; Poorandokht Afshari and Mitra Tadayon: Executing of Intervention; Sedighe Manochehri and Poorandokht Afshari: Writing the article, Article revision.

\section{Funding/Support}

This study was funded by the Research Council of Nursing and Midwifery of Jundishapur University of Medical Sciences of Ahvaz, Ahvaz, IR Iran.

\section{References}

1. Bromberger JT, Harlow S, Avis N, Kravitz HM, Cordal A. Racial/ethnic differences in the prevalence of depressive symptoms among middle-aged women: The Study of Women's Health Across the Nation (SWAN). Am J Public Health. 2004;94(8):1378-85.

2. Speroff L. Clinical Cynecology Endocrinology And Infertility. 6 edNew York: Lippincott; 2005.

3. Bahri N, Afeyat M, Agha Mohamadian H, Noghabi A, Bari N. Investigating the Relationship between Severity of Menopausa Symptoms and Depression, Anxiety and Other Menopausal Symptoms. IJOGI. 2013;16(43):14-20.

4. Cooke JR, Ancoli-Israel S. Sleep and its disorders in older adults. Psychiatr Clin North Am. 2006;29(4):1077-93.

5. Strine TW, Chapman DP, Kobau R, Balluz L. Associations of self-reported anxiety symptoms with health-related quality of life and health behaviors. Soc Psychiatry Psychiatr Epidemiol. 2005;40(6):432-8.

6. Blumel JE, Cano A, Mezones-Holguin E, Baron G, Bencosme A, Benitez Z, et al. A multinational study of sleep disorders during female mid-life. Maturitas. 2012;72(4):359-66.

7. Reed SD, Newton KM, LaCroix AZ, Grothaus LC, Ehrlich K. Night sweats, sleep disturbance, and depression associated with diminished libido in late menopausal transition and early postmenopause: baseline data from the Herbal Alternatives for Menopause Trial (HALT). Am J Obstet Gynecol. 2007;196(6):593 e1-7.

8. Yassary F, Afshary P, Tadayon M, Komeili Sani H, Haghighyzade $\mathrm{MH}$. [Frecuency of Depression and Realated Factors in Postmenopause Women Refering to the Health Center in Dezful]. J of med Jundishapur. 2010;10(6):665.

9. Taroyardi M, Shabani A. Assessment of Psychological Problems In Menopause Women And Relationship's Between Individual And Social Characteristic And Menopausal Symptoms In Referred To Tabriz Educational HospitalS In 2005-2006. J of Urmia Nursing And Midwifery Faculty. 2007(1):1.

10. Dolatian M, Bakhteh A, Valaie N, Afshar F. [Prevalence of Menopausal Related Depression and Its Relative Factors].J of Kermansha Uni of Med Sci. 2006;10(10):76.

11. Timur S, Sahin NH. The prevalence of depression symptoms and influencing factors among perimenopausal and postmenopausal women. Menopause. 2010;17(3):545-51.

12. Sarrel PM. Women, work, and menopause. Menopause. 2012;19 (3): 250-2.

13. Reed SD, Ludman EJ, Newton KM, Grothaus LC, LaCroix AZ, Nekhlyudov L, et al. Depressive symptoms and menopausal burden in the midlife. Maturitas. 2009;62(3):306-10.

14. Zeraati F, Seif Rabie MA, Araqchyan M, Sabouri T. Assessment of quality of sleep and use of drugs with sedating properties in adult patients hospitalized in Hamadan Ekbatan Hospital. Sci J Hamdan Univ Med Sci. 2009;16(4):31-6.

15. Taibi DM, Vitiello MV, Barsness S, Elmer GW, Anderson GD, Landis CA. A randomized clinical trial of valerian fails to improve self-reported, polysomnographic, and actigraphic sleep in older women with insomnia. Sleep Med. 2009;10(3):319-28.

16. Llaneza P, Garcia-Portilla MP, Llaneza-Suarez D, Armott B, Perez Lopez FR. Depressive disorders and the menopause transition. Maturitas. 2012;71(2):120-30.

17. Bauld R, Brown RF. Stress, psychological distress, psychosocial factors, menopause symptoms and physical health in women. Maturitas. 2009;62(2):160-5.

18. Blake J. Menopause: evidence-based practice. Best Pract Res Clin Obstet Gynaecol. 2006;20(6):799-839.

19. Graziottin A, Serafini A. Depression and the menopause: why antidepressants are not enough? Menopause Int. 2009;15(2):76-81.

20. Hartmut P, Jacques B. Standard practice in sexual medicine.Philadelphia: Blackwell; 2006.

21. Sadock JB, Sadock AV. Comprehensive textbook of psychiatry. 7 edNew York: Lippinocott-Williams \& Wilkins; 2007.

22. Beigi M, Javanmardi Z, Abdolahi M. A Study on women's sexual functioning disorders before and after menopause. Scientific 
Journal of Hamadan Nursing \& Midwifery Faculty. 2008;16(2):37-47.

23. Veras AB, Rassi A, Yukizaki LMG, Novo LD, Franco FS, Nardi AE. Impact of depressive and anxiety disorders over menopause manifestations. Revista de Psiquiatria do Rio Grande do Sul. 2007;29(3):315-20.

24. Taavoni S, Ekbatani N, Haghani H. [Sleep disturbance associated factors in menopausal women]. Journal of Kermanshah University of Medical Sciences. 2011;15(4).

25. Lam RW, Michalaak EE, Swinson RP. Assessment scales in depression, mania and anxiety.Oxfordshire: Taylor \& Francis; 2005.

26. Bech P, Gram LF, Dein E, Jacobsen O, Vitger J, Bolwig TG. Quantitative rating of depressive states. Acta Psychiatr Scand.1975;51(3):161-70.

27. Shojaiyan Z, Abediyan Z, Mokhber N, Mazloom SR. Assessment of the Relationship between Menopausal Symptoms and Severity of Depression in Postmenopausal Women. Obstetrics, Gynecology and Infertility Iran J. 2007;9(2).

28. Polisseni AF, de Araujo DA, Polisseni F, Mourao Junior CA, Polisseni J, Fernandes ES, et al. [Depression and anxiety in menopausal women: associated factors]. Rev Bras Ginecol Obstet. 2009;31(1):28-34.
29. Yaktatalab SH, Parsanrgad ME, Jahanmiri S. The effect of group psychotherapy on depression and anxiety in infertile women. Jundishapur Sci Med J. 2004:43-9.

30. Dennerstein L, Guthrie JR, Clark M, Lehert P, Henderson VW. A population-based study of depressed mood in middle-aged, Australian-born women. Menopause. 2004;11(5):563-8.

31. Li Y, Yu Q, Ma L, Sun Z, Yang X. Prevalence of depression and anxiety symptoms and their influence factors during menopausal transition and postmenopause in Beijing city. Maturitas. 2008;61(3):238-42.

32. Cuadros JL, Fernandez-Alonso AM, Cuadros-Celorrio AM, Fernandez-Luzon N, Guadix-Peinado MJ, del Cid-Martin N, et al. Perceived stress, insomnia and related factors in women around the menopause. Maturitas. 2012;72(4):367-72.

33. Choi H, Lee D, Lee K, Kim H, Ham E. A structural model of menopausal depression in Korean women. Arch Psychiatr Nurs. 2004;18(6):235-42.

34. Yangin HB, Sozer GA, Sengun N, Kukulu K. The relationship between depression and sexual function in menopause period. Maturitas. 2008;61(3):233-7. 